\title{
INNOVATION TECHNOLOGIES IN SOFT FRUIT PRODUCTION
}

\author{
D. Dunchev* \\ Department of Economics, Agricultural University - Plovdiv, Plovdiv, Bulgaria
}

\begin{abstract}
The global challenges associated with climate change, food security and the growing instability with land and water shortages are changing the agriculture. The innovation technologies are crucially important to meet those issues and to improve productivity and sustainability of agricultural production. The aim of the study is to analyze the innovative technologies that could help farmers to improve soft fruit producing. The paper uses various methods of analysis - graphic, comparative and statistical. The new technologies in high-tech greenhouse horticulture are observed. The survey focuses on sensors (sensors for measuring water and air temperature, advanced sensors to determine microclimate and the activity of the crop) energy solutions, production technology, polytunnels, precision irrigation and robotics. The results indicate that the innovation technologies could improve water and nutrient use efficiency, increase yields and reduce the environmental impact. The innovation technologies in fruit sector are also important for human health. The implementation of innovative methods could stimulate the production of quality fruits which are environmentally friendly and internationally competitive.
\end{abstract}

Key words: sustainability, precision agriculture, precision irrigation, microclimate, polytunnels

\section{INTRODUCTION}

Agricultural sector is facing various challenges including: increasing population, shortage of resources and climate changes. Those challenges are leading to invention and application of new agricultural technologies as ways to increase productivity and the efficiency with lower environmental impact. In the past two decades many innovations have been introduced and implemented .The innovation technologies are crucially important to meet the global issues and to improve sustainability of agricultural production. The aim of the study is to analyse and compare the innovative technologies in agriculture and assess their opportunities in soft fruit producing.

The first part of the paper presents the methods of the survey and theoretical background related to the concept of innovations in the soft fruit industry. The second part of the paper focus on the case trails and economic benefits

Correspondence to: Dobri Dunchev, Department of Economics, Agricultural University - Plovdiv, 12 Medeleev Bld., 4000 Plovdiv, Bulgaria, e-mail:

dobri.dunchev@yahoo.com of innovations. In the third part are analysed the opportunities for implementations and developing the innovations in the soft fruit industry in Bulgaria.

\section{MATERIALS AND METHODS}

The paper is based on the results from own research for the period 2015-2018. The study is part of $\mathrm{PhD}$ dissertation. There are held interviews and surveys with the soft fruit growers as some of them are the biggest enterprises in the country. The survey also compares different innovation technologies in the soft fruit sector and their development in the UK and Bulgaria. The focus of the interviews is on the benefits of innovation technologies.

\section{THEORETICAL BACKGROUND}

In the past 50 years, the topic related to the innovation and innovation technologies is highly relevant. A number of studies apply Schumpeter's hypotheses to consider the characteristics of the market and the company as the main drivers of the innovation process (Martinez-Ros, 2000). 
According to Schumpeter's model, the innovation process is triggered by an idea, and when it reaches the market becomes a real innovation. At the end of the process, it is part of the usual practice and procedures (Schumpeter, 1939).

The implementation and management of the innovation process in agriculture is more complicated and complex. Therefore, the surveys on the innovation process in the sector are highly fragmented. In addition, there are a number of peculiarities in the agricultural sector that affect the development of the innovation process. Consequently in agriculture it is difficult to summarize the diffusion and development of innovations (Crossan and Apaydin, 2010). Most of the studies related to innovation management in the agriculture focuses on case studies conducted in large farms (Christensen et al., 1996; Huiban and Bouhsina, 1998), while studies on small farms are much less developed (Avermaete et al., 2004).

On the other hand, innovation technologies are very important for the sector. Innovation could help for improving productivity, competitiveness and is playing a major role in creating employment, generating income, poverty reduction and social exclusion. FAO defines agricultural innovation as the process by which a person or organization introduces the use of new or improved products, processes or forms of organization in society or economy to increase efficiency, competitiveness, sustainability, thereby helping to achieve food security, economic development and sustainable natural management (FAO 2015).

Over the last decades, there have been significant changes in European farming patterns. While some of the farms continue increasing productivity by application of traditional practices, new farming methods develop and diversify. Organic and biodynamic farming, precision agriculture, agro-ecology, mixed farming. These new models lead to the development of innovative technologies. Because of the resources scarcity in agriculture, the strong dependence on natural factors, farmers and processors need to develop innovations related not only to new machines, processes and techniques but also new business management models. Innovation in the agriculture is the result of cooperation between various actors in the sector: farmers, processors, distributors and consumers.
Precision farming is linked to the new farming models and it is in the centre of invention and implementation of new technologies.

Precision agriculture is a key component of the modern agricultural revolution. There are many definitions of Precision Agriculture but the first actual definition came from the US House of Representative (1997), which defined $\mathrm{PA}$ as "an integrated information- and production-based farming system that is designed to increase long term, site-specific and whole farm production efficiency, productivity and profitability while minimizing unintended impacts on wildlife and the environment". Other definition of Precision Agriculture is a way to "apply the right treatment in the right place at the right time" (Gebbers and Adamchuk, 2010). It is a farming management concept based upon observing, measuring and responding to inter and intrafield variability in crops or in aspects of animal rearing.

\section{CASE STUDIES}

There have been analysed four different cases in order to illustrate the effect of innovation technologies on production in soft fruit sector. The group of soft fruits includes: raspberries, strawberries, blackberries, blueberries, etc. The importance of these fruits over the last two decades has increased due to their classification as sources of valuable vitamins for human health and bio antioxidants. The technologies used in their production in the last years have been a significant progress due to the development of innovations in agriculture and the improvement of technology in precision agriculture. The traditional cultivation of soft fruit outdoors has been replaced by alternative methods that prove to be much more effective. In Western Europe, America and Australia, these fruits are grown entirely in polyethylene tunnels, ' glass greenhouses ', using precision technologies to control the conditions of their cultivation. These technologies allow the control and creation of microclimate, which is the most valuable for the cultivation of fruits. This is achieved with the use of precision technologies using smart sensors for reading and controlling humidity, temperature, level of $\mathrm{CO} 2$, precise irrigation, pests and diseases control, etc.

For the purpose of the analysis blackberries have been chosen, the same variety in the four different cases. All technologies are applicable to the cultivation of other crops in the sector 
(raspberries, strawberries, blueberries, etc.). The yields are averaged based on the three years (2015-2018) of observation. The results of other farms in the sector were took into account, analyzed and some consultation have been made.

\section{Open field}

The plants are planted in the soil on the beds. Yields with this system of growing blackberries are 10 tons per hectare (Figure 1). This is an optimal yield under good climatic conditions. In the case of frosts or rains during fruiting, yields can be much smaller. In some years, there has been a complete destruction of the harvest. In the UK and other Western European countries, the cultivation of soft fruit on open areas in decreasing. This system is considered outdated and not effective. The high risk of crop destruction and low quality of production has led farmers to look for different innovative fruit growing systems. Another reason for introducing the new technologies for soft fruit farming is the supermarket's quality requirements.
In the study the open field case is considered as a base in order to compare it with other cases where different technologies are described.

\section{Standard polytunnel construction}

In the standard tunnel plants are planted not in the soil, but in pots. The soil is replaced from different substrate mixtures. The most used mixture is of peat and coconut fibers. This system of cultivation uses drip irrigation, which is automated and it is controlled by a worker through a computer system. There are installed sensors which monitor: temperature and humidity. The aim is to ensure optimum growing conditions for the plants. The human factor in this case is with a high importance. Although the measurement of all indicators are automated, the processes themselves are physically performed by humans.

The average yields in this case of growing blackberries are 32 tonnes per hectare, which is 3.2 times more than the yields of blackberries grown on open areas (Figure 1).

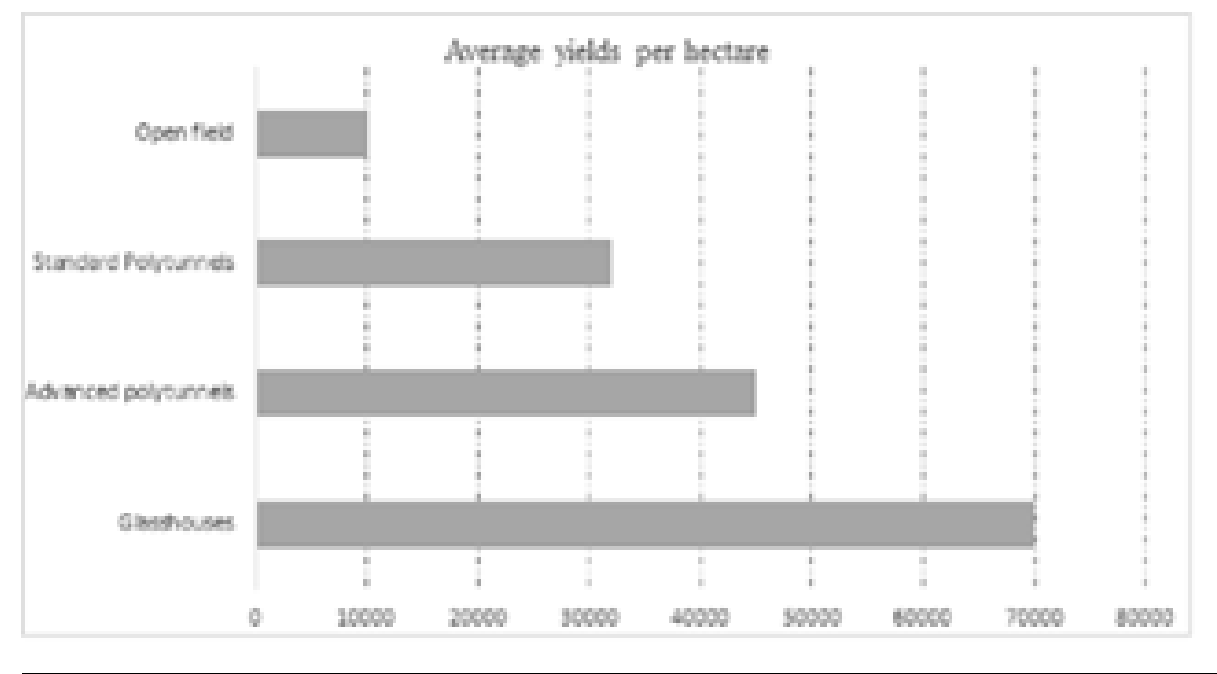

Figure 1. Average yields per hectare: 2015-2018

\section{Advanced polytunnel construction}

There are various polytunnel constructions on the market with different brand names. The usage of word 'advanced' in the paper shows the difference between standard polytunnel and new generation polytunnels.

There is a precise irrigation system in the advanced tunnel construction. The difference from the second case is that the moisturemeasuring sensors submit information that irrigation is necessary and turns on automatically. When optimum moisture is achieved, the sensors transmit information and the system stops. This cycle is repeated 24 hours in a day. These very high-level tunnels are higher, which is better for the air exchange. That is with a high importance for achieving optimum results. The optimum air exchange is also a significant factor for guarantee the best moisture and temperature levels which deliver better results. The microclimate is guaranteed with an automatic system for opening and closing the tunnels. This leads to elimination of the human factor in controlling the microclimate. 
The average yields of this system of growing blackberries are 45 tonnes per hectare, 4.5 times more than open field (Figure 1).

\section{Glasshouses}

This is the most precise system for growing soft fruits. There is a full automation of the production process. There are systems which aims to implement four main functions: Climate management, Water Management, Energy Management and Data management.

- Climate management

Air temperature, humidity, $\mathrm{CO}_{2}$ content and the proper balance of growing lights are essential conditions for a healthy and vigorous crop. By regulating the greenhouse climate in a proper manner, the chance of disease and plagues is reduced. The precise sensors allow for perfect cooperation of all the climate processes such as heating, shading, ventilation and lighting. Detailed overviews and graphs provide insight into the conditions inside and outside the greenhouse. The climate regulation not only takes the current weather conditions into account, but also weather forecasts. For example, the greenhouse temperature can be adjusted according to the type of weather for the coming days and the windows can even be closed before an approaching rainstorm. At any moment of the day, regardless of the conditions, the system creates an ideal growth climate fully tailored to the plants' requirements. The efficient climate regulation improves the quality of the fruits and increase crop efficiency.

\section{- Water Management}

Water and fertilizers are essential to the growth of the crop. However, these resources are becoming increasingly scarce worldwide. Modern horticulture has various possibilities for saving water and fertilizers. For example, recirculation of drain water reduces consumption by at least $30 \%$. Exact alignment of the plant's needs and the irrigation also provides an important contribution to savings. An associated advantage is that an optimal irrigation strategy will increase the crop performance and profit. The process computer precisely coordinates the dosage of various water sources such as rainwater, well water and drain water with the demands of the crop. The software anticipates changing conditions pro-actively. For example, the frequency and duration of irrigation sessions are adjusted prior to times of more or less sunshine. Based on the measured water intake of the plants and the water content of the soil or substrate, the irrigation can be tailored even more precisely to the growth process._That system achieves optimum crop results under all conditions and save on the consumption of water and fertilizers.

- Energy management

A growth climate with the proper ratio of light, warmth and $\mathrm{CO}_{2}$ dosage ensures high production and quality. The most important sustainable source of growing light and warmth for the crop process, the sun, is not always sufficiently available. That's why supplemental energy should be used. However, fossil energy sources, such as natural gas and petroleum are becoming ever scarcer and more expensive and they burden the environment. Efficient management of energy processes and $\mathrm{CO}_{2}$ dosage, therefore, are necessary for sustainable production and for the company profit.

That system allows excess heat to be stored in reservoirs for use later. Absolutely all processes and systems in the company can be coordinated with each other seamlessly. The unique software even effortlessly manages complex processes such as heat transfer among adjacent cluster companies. All energy processes and $\mathrm{CO}_{2}$ dosages are aligned with the needs of the crop in order to achieve strong growth and high production. For generating energy, the most effective source is chosen at each moment. The energy efficiency is increased and, at the same time, provide substance to sustainable company operations.

- Data management

Managing the horticultural company demands insight into various processes. For the cultivation of the crop, there is collected information about the glasshouse climate and water and energy use. In addition, that system uses lower labour costs, inventory and planning - among other things. Good control of production and quality, along with the management of costs and yields are essential for the company profit. This means that all the information from the various sources must be structured, stored and displayed in an orderly manner. Only then is targeted information analysis possible in order to arrive at an assessment and improvement.

All data concerning the performance of personnel, cultivation and harvesting activities, production costs, inventory control and diseases and plagues are registered to the management information system. 
The total business operations are based on current and reliable data. All these can be used for data analysis, comparison and process improvement.

The average yields of this system of growing blackberries are 70 tonnes per hectare, which is 7 times more than open field (Figure 1).

\section{INTRODUCING NEW TECHNOLOGIES IN BULGARIA}

Soft fruits as strawberries and raspberries are traditional for Bulgaria, while blackberries and blueberries are getting more popular and just entering the market. The climate conditions in the country determine seasonality of the production of soft fruits. The main purpose of implementing polytunnels and glasshouse production is to guarantee longer harvest season and to provide fresh fruits to the market. The economic importance of polytunnel and glasshouse production is linked to the fact that higher incomes could be obtained. They are based on significantly higher yields compared to the open field yields.

The production of soft fruits on open fields, which is still practiced in Bulgaria, is considered ineffective and almost not applicable in Western Europe, America and Australia. The weather conditions such as wind, rain, direct sunlight etc. could affect the quality levels to the fresh fruits. The requirements of the supermarkets in Europe have imposed quality standards for soft fruits. One of the requirements is fruits not to be grown outdoor. Over the past five years, the interest in the consumption of these fruits has also raised in Bulgaria and the leading supermarkets are increasing the supply of soft fruits and implemented different standards. This has put many of the local producers at a disadvantage and forced them to seek and enforce in their practices the world methods of cultivation with covering the crop and research innovative methods. The first use of polytunnels in Bulgaria dates in 2016 with few soft fruit farmers. The covered areas with polytunnels are still very limited in Bulgaria. Based on own study until 2018 there are registered : 3 hectares of raspberries, 4 hectares of blackberries, 2 hectares of strawberries and 1 hectare of blueberries. One of the reasons for the limited usage is the high prices of these technologies. Another factor is the lack of trained professionals to implement the new innovative technologies.
It is expected that in the new EU programming period after 2020 the farmers will have a strong interest of purchasing new-generation polytunnels and their equipment with precise technologies for management and control of the production process.

\section{CONCLUSIONS}

Based on the analysis some conclusions could be drawn:

- Innovation technologies in the soft fruit farming as an emerging concept, are developing rapidly in the last two decades, helping farmers to achieve optimal growing conditions and higher yields.

- The study is comparing open fields with different polytunnels and glasshouse growing systems. The best yields results are achieved in the fourth case, described on the paper, glasshouse growing system, but investment cost is the highest.

- Despite of the requirement for higher investments, the growers should consider implementing that technologies in order to be able to compete on the market and to meet the supermarket quality standards.

- Innovation technologies could increase not only the quantity but also the quality of the fruits which is an important requirement from the supermarkets selling fresh fruits.

- Innovation technologies could be an answer for a lot of challenges associated with the climate change and environment protection. The new technologies reduce not only the cost of production, but also environmental impact and contribute for the food security.

- On the other hand, there are still many raising questions related to the adoption of the new techniques. The need of skilled labor, the investment cost, lack of support and advisory services are obscuring the process in Bulgaria at the moment. That is expected in a nearly future to be changed as the need of using the new technologies is rising.

\section{REFERENCES}

1. Avermaete, T., J. Viaene, E.J. Morgan, E. Pitts, N. Crawford and D. Mahon, 2004. Determinants of product and process innovation in small food manufacturing firms. Trends in Food Science \& Technology, 15(10): 474-483

2. Joint Research Centre (JRC) of the European Commission; Monitoring Agriculture ResourceS (MARS) Unit H04; Pablo J. Zarco-Tejada, Neil Hubbard and Philippe Loudjani. Precision agriculture: 
An opportumity for EU - Potential support with the CAP 2014-2020

3. Christensen, J.L., R. Rama and N. von Tunzelmann, 1996. Innovation in the European food products and beverage industry. EIMS publication 35, Aalborg University Press, Aalborg, Denmark

4. Crossan, M.M. and M. Apaydin, 2010. A multi-dimensional framework of organizational innovation: a systematic review of the literature. Journal of Management Studies, 47(6): 1154-1191.

5. John V. Stafford. Keynote paper. Implementing Precision Agriculture in the $21^{\text {st }}$ Century. J. agric. Engng Res. (2000) $76,267\} 275$
6. FAO (2015), The State of Food and Agriculture: Innovation in family farming, Rome Italy

7. Huiban, J.P. and Z. Bouhsina, 1998. Innovation and the quality of labour factor: an empirical investigation in the French food industry. Small Business Economics, 10: 389-400.

8. Martinez-Ros, E., 2000. Explaining the decisions to carry out product and process innovation: the spanish case. The Journal of High Technology Management Research, 10(2): 223-242.

9. Schumpeter, J.A., 1939. Business cycles: a theoretical, historical and statistical analysis of the capitalist process. McGraw-Hill Book Company, Columbus, OH, USA. 